This item was submitted to Loughborough's Research Repository by the author.

Items in Figshare are protected by copyright, with all rights reserved, unless otherwise indicated.

\title{
Teaching the substitutive conception of the equals sign
}

PLEASE CITE THE PUBLISHED VERSION

http://dx.doi.org/10.1080/14794802.2012.756635

PUBLISHER

Routledge (Taylor \& Francis) / @ 2013 Copyright British Society for Research into Learning Mathematics

VERSION

AM (Accepted Manuscript)

LICENCE

CC BY-NC-ND 4.0

REPOSITORY RECORD

Jones, lan, Matthew Inglis, Camilla K. Gilmore, and Rhys Evans. 2019. "Teaching the Substitutive Conception of the Equals Sign". figshare. https://hdl.handle.net/2134/12552. 
This item was submitted to Loughborough's Institutional Repository (https://dspace.lboro.ac.uk/) by the author and is made available under the following Creative Commons Licence conditions.

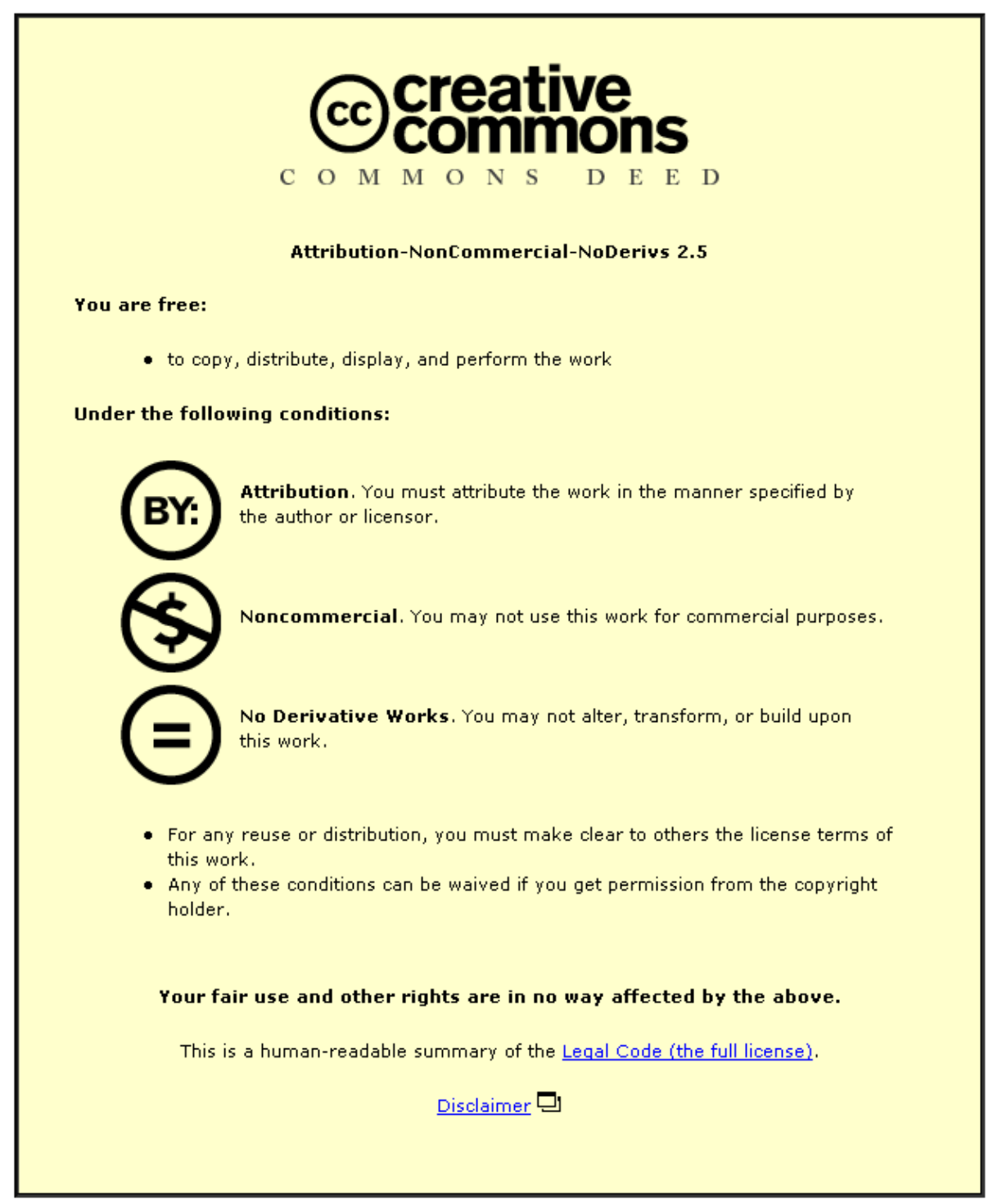

For the full text of this licence, please go to: http://creativecommons.org/licenses/by-nc-nd/2.5/ 
Teaching the substitutive conception of the equals sign

Ian Jones, Matthew Inglis, Camilla Gilmore and Rhys Evans

Mathematics Education Centre, Loughborough University, Loughborough, United Kingdom 


\begin{abstract}
A cumulative body of research has shown that children typically shift from an operational to a relational conception of the equals sign as they move through schooling. Jones (2008) argued that a truly relational conception of the equals sign comprises a substitutive component and a sameness component. Here we present two studies that build on this argument. The first investigated how the equals sign is typically presented to primary children in England, and we report that in the main an operational conception seems to be promoted. The second study measured the impact of a specially designed intervention on early secondary children's conceptions of the equals sign. Pre- and post-test data revealed that the intervention promoted substitutive and sameness components of symbolic equivalence. We consider the theoretical and pedagogical implications of the results.
\end{abstract}

Keywords: substitution; equivalence relations; equals sign

\title{
Introduction
}

A flexible understanding of symbolic equivalence relations is essential for a conceptual understanding of many branches of mathematics. Much research has investigated how children move from an operational understanding of the equals sign in their early years of schooling to a more relational understanding in later years (Baroody and Ginsburg 1983; Behr, Erlwanger and Nichols 1976; Denmark, Barco and Voran 1976; Kieran 1981; McNeil 2008; McNeil et al. 2011; Rittle-Johnson et al. 2011). Jones and Pratt (2012) argued that research to date has operationalised the relational understanding of the equals sign exclusively in terms of sameness. That is, researchers consider a sophisticated understanding of the equals sign to involve viewing the symbol "=" as meaning "is the same as", and accepting operators on both sides of an arithmetic statement. We refer to this as the sameness-relational conception of the equals sign. ${ }^{\mathrm{i}}$ Jones and Pratt further argued that research into children's understanding of equality has overlooked the important notion of substitution. According to Jones and Pratt, a 
sophisticated understanding of the equals sign also involves viewing " $="$ as meaning "can be substituted for" and viewing arithmetic statements as rules for making exchanges of notation. We refer to this as the substitutive-relational conception of the equals sign.

Jones (2008) investigated whether the substitutive-relational conception is distinct from the sameness-relational conception. He developed a computer-based arithmetic notating task, called Sum Puzzles, in which arithmetic statements can be used to make transformations of arithmetic notation towards a specified task goal. He found that the children viewed the statements in terms of substitution rather than sameness during the task, and so the substitutive-relational conception of the equals sign may be cognitively distinct to the sameness-relational conception. However, Jones' study suffered two limitations. First, no attempt was made to establish the children's prior knowledge of arithmetic equivalence before they worked with the software. Second, no attempt was made to measure any impact on how children viewed the equals sign after working with the software. Here we present two studies that address these limitations. Our overall aim is to gather evidence of children's conceptions of the equals sign at the conclusion of primary schooling in England, and to measure the impact of the substitutive tasks developed by Jones on the conceptions of a sample of children in the first year of secondary schooling.

\section{Children's conceptions of the equals sign}

A coherent body of literature on children's difficulties associated with the equals sign has accumulated over recent decades. A key finding is that young children tend to view “=” as an operator symbol, akin to "+", “ $\times ”$ and so on, rather than as denoting an equivalence relation (Baroody and Ginsburg 1983; Behr, Erlwanger and Nichols 1976; 
Carpenter, Franke and Levi 2003; Kieran 1981; Knuth et al. 2006; Renwick 1932). This operational conception manifests itself as an expectation that the equals sign means "work out the answer" and should always be preceded by an expression and followed by a result. The conception arises from and is reinforced by the way arithmetic statements are presented in mathematics classrooms and textbooks (Baroody and Ginsburg 1983; Li, Ding, Capraro and Capraro 2008; McNeil et al. 2006; Rittle-Johnson et al. 2011; Seo and Ginsburg 2003), and over time becomes ingrained, hindering arithmetic and algebraic performance (Knuth et al. 2006; McNeil 2004; McNeil and Alibali 2002). When children enter secondary school they meet new areas of mathematics, notably symbolic algebra, for which the operational conception proves increasingly unsuccessful (McNeil 2007). As they move through secondary school many children gradually develop a sameness-relational conception of the equals sign in which " =" is seen as meaning "is the same as" and a wide variety of statement types are accepted (Knuth et al. 2006; McNeil et al. 2011; Rittle-Johnson et al. 2011).

There is widespread agreement that children's difficulties are due to how the equals sign is presented in classrooms rather than due to developmental limitations (Baroody and Ginsburg 1983; R. M. Capraro et al. 2010; Cobb 1987; Li et al. 2008; McNeil 2008; Rittle-Johnson et al. 2011; Seo and Ginsburg 2003; Sherman and Bisanz 2009). Analyses of mathematics student textbooks and teacher guidebooks for primary and middle grades in the U.S. revealed that the equals sign is rarely defined and is often used interchangeably with computational terms such as "makes" (Li et al. 2008; McNeil et al. 2006; Rittle-Johnson 2011; Seo and Ginsburg 2003). Moreover, the majority of arithmetic statements presented in textbooks are in canonical form i.e. of the form expression $=$ result and rarely contain operations on both sides of the equals sign. These presentations can be expected to promote an operational rather than a sameness- 
relational understanding of the equals sign (Cobb 1987; Li et al. 2008; McNeil 2008; McNeil et al. 2011). These studies have all been carried out in the US and, while the assumption has frequently been made that children in England receive similar exposure to the equals sign, no data exists to date.

Numerous intervention studies have investigated how primary and secondary children might better be helped in moving from an operational to a relational conception (e.g. Denmark et al. 1976; Sáenz-Ludlow and Walgamuth 1998; Carpenter et al. 2003; Pirie and Martin 1997; Molina, Encarnación Castro and Enrqiue Castro 2009). These interventions usually include presenting children with arithmetic statements in a wide variety of formats and asking them to establish their truthfulness. The presented statements often appeal to underlying arithmetic principles commutativity, compensation and so on, like the examples shown in Table 1. The intent is to encourage children to see the sameness of the expressions on both sides of the equals sign without needing to work out and compare each expression's computational result. For example, if a student knows that the order of addends is unimportant (commutative property of addition) then she can establish the truthfulness of $10+4=4+10$ without recourse to computation. Children's understanding is typically assessed in terms of their performance with such statements, and by tasks in which they construct or judge definitions of the equals sign.

Insert Table 1 about here 


\section{Substitution}

Jones and Pratt (2012) argued that a sophisticated understanding of the equals sign also includes the important mathematical idea of substitution. Evidence for a distinct substitutive component in arithmetic contexts comes from two sources, qualitative studies based on specially designed software called Sum Puzzles ${ }^{i i}$ (Jones 2008), and quantitative studies based on a definitions-based Conceptions of the Equals Sign (CES) instrument adapted from the literature (Jones et al. 2012).

The Sum Puzzles software presents pupils with a series of puzzles to solve such as the example shown in Figure 1. The goal is to transform the expression in the large box at the top of the puzzle $(31+67$ in the case of Figure 1) into a single result (98 in this case). This can be achieved by using the provided arithmetic statements to make substitutions. For example, a pupil might start by selecting the statement $31=30+1$ and using it to substitute $30+1$ for 31 in the expression at the top of the screen, thereby transforming the expression from $31+67$ into $30+1+67$. The selection of statements for making substitutions in the expression can continue in this manner until the expression is the single result 98 at which point the puzzle has been solved. Jones (2008) investigated the distinctiveness of the substitutive-relational conception from the sameness-relational conception by presenting children with puzzles containing both true and false statements. He found that children were oblivious to the truth or falsity of the presented statements when using them to make substitutions. For example, the children just as readily used a true statement such as $88=33+55$ to substitute 88 for $33+55$ as they did a false statement such as $77=11+33$ to substitute 77 for $11+33$. This indicated that children were able to focus on the substitutive-relational conception without also considering the sameness-relational conception. 
Insert Figure 1 about here

The CES instrument was adapted from Rittle-Johnson and Alibali (1999) and contains twelve fictitious definitions of the equals sign, and children are asked to rate the cleverness of each definition on a three-point scale ("not so clever", "sort of clever", "very clever"). The original instrument has been used extensively to explore children's operational and sameness-relational conceptions of the equals sign (e.g. McNeil and Alibali 2002, 2005; Rittle-Johnson et al. 2011) and the instrument was adapted to consider the sameness-substitutive conception as well. In the adapted instrument, three of the twelve definitions correspond to the operational conception, three to the sameness-relational conception, three to the substitutive-relational conception, and three are distractor definitions that have no meaning in terms of equals sign conceptions, shown in Table 2. Jones et al. (2012) administered the CES instrument to 243 children in the first year of secondary school in England and China. A Principal Components Analysis revealed the operational, sameness-relational and substitutive-relational conceptions to be clearly distinct from one another. This result was replicated with another sample of 133 children from England and China, and again with a sample of 99 children from England (Jones, Inglis and Gilmore 2011), suggesting the distinctiveness of the sameness-relational and substitutive-relational conceptions is a robust result.

Further evidence is required for the substitution meaning to become a fully accepted component of a relational understanding. In this article we contribute evidence in terms of pupils' existing conceptions and the impact of a teaching intervention designed to promote a substitutive-relational view of the equals sign. 


\section{Substitution and task design}

The sameness-relational and substitutive-relational meanings afford distinctive task design opportunities. As described above, tasks typically used in intervention studies that operationalise the relational meaning of the equals sign exclusively in terms of sameness include presenting children with different types of arithmetic statement and asking them to establish their truthfulness (e.g. Carpenter, Franke and Levi 2003; Denmark et al. 1976; Molina, Encarnación Castro and Enrqiue Castro 2009). We highlight here three contrasting design opportunities afforded by the substitutiverelational meaning.

First, the sameness-relational and substitutive-relational meanings lend themselves to presenting arithmetic statements to pupils in different ways. The substitutive-relational meaning suggests the use of arithmetic statements to make substitutions of notation, as for simultaneous equations in simple algebra. We can therefore present pupils with sets of interconnected arithmetic statements, as in Figure 1, which can be used to transform one another. Conversely, the sameness-relational meaning suggests establishing whether the expressions on both sides of a particular arithmetic statement have the same value. When the research or pedagogic focus is on sameness it is therefore common to present pupils with individual statements for evaluation (e.g. Behr et al. 1976; Knuth et al. 2006; McNeil 2008), as described above.

Second, the sameness-relational and substitutive-relational meanings lend themselves to viewing arithmetic statements in different ways. The parallel statements 
in Figure 1 can be searched for matches of notation to establish where substitutions might be made. In previous studies (Jones 2008; Jones and Pratt 2012) pupils identified numerals in the expression 31 and 67 in Figure 1 and searched for them within the presented statements in order to identify which statements could be used to make substitutions $(31=30+1$ and $67=60+7$ in Figure 1$)$. In contrast, where the focus is exclusively on sameness, the literature reports students scrutinising both sides of the equals sign to evaluate whether the two expressions have the same value (e.g. Carpenter et al. 2003; Denmark et al. 1976; Molina, Encarnación Castro and Enrqiue Castro 2009).

We acknowledge that the visual pattern matching required to identify where substitutions can be made is a rather superficial activity, but it is the basis of a distinctive way to offer pupils engagement with general arithmetical principles, such as those in Table 1. Jones and Pratt (2012) reported children articulating arithmetic principles in terms of visual transformations of symbol strings on the computer screen. For example, in Figure 1 when pupils used $31=30+1$ to transform the expression at the top of the screen from $31+67$ into $30+1+67$ they typically described the statement as "splitting up" or "separating" the 30 and the 1 contained in 31 . Similarly, when pupils used the statement $1+60=60+1$ to substitute $1+60$ for $60+1$ they typically described the statement as "swapping round" or "switching" the 1 and the 60 . In contrast, the wider literature reports pupils accessing arithmetic principles by using computational shortcuts to evaluate sameness without needing to work out the value on each side of the equals sign. For example $10+4=4+10$ is self evidently true if the commutative property of addition is known (Baroody and Ginsburg 1983; (Molina, Encarnación Castro and Enrqiue Castro 2009). As such, the substitutive-relational and 
sameness-relational meanings offer distinctive ways for designers to engage pupils with the structure of arithmetic statements.

\section{Research focus}

In the remainder of the paper we present two studies. Study 1 was designed to establish how the equals sign is typically presented in primary schools in England, and so guide our expectations of children's conceptions in the first year of secondary school. Study 2 was designed to measure the conceptions of a sample of children in the first year of secondary school, and to measure the impact of a teaching intervention based around a substitutive-relational meaning of the equals sign. The combination of Studies 1 and 2 also enabled us to compare our general expectations of children's conceptions of the equals sign with those actually measured in the sample of children prior to the intervention.

\section{Study 1: How is the equals sign presented in primary classrooms in England?}

The literature on children's conceptions of the equals sign suggests that how the symbol " $=$ " is presented in classrooms is a predictor of children's understanding of symbolic equivalence. Studies to date have analysed textbooks in the U.S. and China (Li et al. 2008; McNeil et al. 2006; Rittle-Johnson 2011; Seo and Ginsburg 2003), but no equivalent analysis has been conducted for the case of England. However, an analysis of equivalent textbooks in England would be of limited use because, unlike in the U.S. and China, primary teachers in England tend to use mathematics textbooks very little, or not at all (Mullis et al. 2008). Instead, "there is widespread use of worksheets with at times dubious quality control" (Askew et al. 2010, 34). In light of this idiosyncrasy we cannot expect to be able draw general conclusions from an investigation of textbooks or 
other classroom resources published for use in classrooms in England. Moreover, even if we were able to do so, we would not expect the picture of how the equals sign is presented to and talked about in primary classrooms in England to be particularly coherent.

In light of these difficulties we turned to the written tests of the statutory National Curriculum assessments for England and Wales, which are administered in the final year of primary school. The tests, which are high-stakes and used for a range of accountability purposes, are regarded to have a large impact on how mathematics is taught and learnt in schools in England (ACME 2007; Children, Schools and Families Committee 2010; NCETM 2009; Ofsted 2008; Wyse and Torrance 2009). As such, the presentation of the equals sign in written test papers can be expected to provide some insight as to how it is presented in primary classrooms England. This in turn can guide our expectations of children's conceptions of the equals sign in the first year of secondary schooling, including the sample of children in Study 2 reported later in the article.

Method. We analysed the statutory National Curriculum written tests sat by children in the final year of primary school ages 10 and 11 years from 2002 through to 2010. Two written tests are produced each year meaning a total of 18 were analysed. We coded every occurrence of the symbol ' $=$ ' in the 18 written tests, using an adaptation of the coding scheme used by McNeil et al. (2006). Occurrences of the symbol "=" were coded as appearing in (i) canonical statements, or (ii) statements of the form expression $=$ expression, or (iii) statements of the form as letter $=$ result. All occurrences fell uniquely into one of these three categories. Two researchers undertook the coding independently and the inter-rater agreement was $100 \%$. 
Analysis and results. The symbol "=" appeared a total of 60 times throughout the written tests, although it did not appear at all in four of the tests. The majority of occurrences 39 out of 60 were in canonical statements. In most cases empty boxes for candidates to write in replaced some numbers or operator signs, as in $11 \times$ $=1111$. A further 5 occurrences of the equals sign were in statements of the form expression $=$ expression, all of which had empty boxes in place of some numbers or operators, as in $20 \_8=4 \_7$. There was 1 occurrence of an equals sign appearing in an instruction ${ }^{\text {iii }}$ which was also coded as expression $=$ expression, meaning a total of 6 equals sign were coded as expression $=$ expression. The remaining 15 occurrences of the equals sign were coded as letter $=$ result, and in every case the number was an empty box for candidates to enter a number, as in $x=$ $\mathrm{cm}$.

Discussion. Analysis revealed that most occurrences (65\%) of the equals sign in the statutory end of primary school written tests were in canonical statements. Canonical statements are known to promote an operational conception of the equals sign, as discussed earlier, and we might therefore expect children at the start of secondary schooling to view the equals sign as an operation. A few occurrences $(10 \%)$ were in statements of the form expression = expression in one case this form was implied - see above, which is likely to promote a sameness-relational conception, and so we might expect children at the start of secondary schooling to adhere to a samenessrelational conception to a limited extent. It should be noted that the association of expression $=$ expression with sameness-relations is an empirical, cognitive result (e.g. Behr et al. 1976) and, mathematically speaking, there is nothing inherently more relational or less operational about one statement form over another. It is therefore possible that, say, expression $=$ expression statements are cognitively more strongly associated with substitution as well as sameness than are canonical statements. 
Interestingly, the remaining occurrences $(25 \%)$ were in statements of the form letter $=$ result. This form of statement is less readily associated with a given conception and has not been included in studies into the equals sign to the best of our knowledge. A plausible case could be made for it supporting any of the three conceptions discussed in this article. The obvious interpretation is that letter $=$ result suggests a substitutiverelational meaning of the symbol " =" where a letter is to be replaced by a number. An example of a question from the tests that contains equals signs coded as letter $=$ result is shown in Figure 2. The use of the phrase "stands for" in Figure 2 further points to the notion of substitution. However it also clear from Figure 2, which is representative of every occurrence of letter $=$ result in the tests analysed, that candidates are not required to make a substitution of a letter with a number. In fact the equals sign can be interpreted solely as a place-indicator for a result and such presentation might therefore promote an operational meaning. Alternatively, it is possible that the form letter $=$ result promotes a sameness-relational view of the equals sign. This would be consistent with evidence that children who adhere to an operational conception reject statements lacking operations as wrong or unfinished (e.g. Behr et al. 1976), and McNeil et al.'s (2011) speculation that statements lacking operations on either side might promote a sameness-relational conception because they are "outside of an arithmetic context" (11). As such, any inference about conceptions promoted by the presentation of the form letter $=$ result must be treated with caution.

Insert Figure 2 about here

In sum, assuming that the analysis of high-stakes tests at the conclusion of primary schooling does provide a reasonable proxy as to how the equals sign is 
presented in classrooms, we can expect that among children in the first year of secondary schooling the operational conception is dominant, and the samenessrelational conception is detectable to some extent. We will consider the implication of this finding for understanding children's conceptions in the General Discussion.

\section{Study 2: Can the substitution meaning of the equals sign be taught?}

In Study 2 we measured the conceptions of the equals sign of a sample of children in the first year of secondary schooling, and then investigated whether the substitutiverelational computer tasks described in Jones (2008) promote a more sophisticated understanding of the equals sign. In light of the literature and the findings of Study 1 we anticipated that the children would more strongly view the symbol "=" as an operator than as a relation prior to the intervention. The tasks used in the intervention have been shown to engage children with making substitutions in previous studies (Jones 2008; Jones and Pratt 2012), and so we expected substitutive-relational conceptions to be stronger after the intervention than before it. In addition the tasks presented children with non-canonical arithmetic statements and so, based on the literature reviewed above, we also expected sameness-relational conceptions to be stronger following the intervention.

Method. The study used a single group pre-test, intervention, post-test design. Two classes of children in the first year of secondary school $N=54$, ages $11-12$ in England participated in the study, from one suburban and one rural school. The children in the suburban class were described as "medium ability" by their mathematics teacher, and the rural class as "mixed ability". Both schools have an above average socioeconomic intake and academic achievement. 
In order to determine how children viewed the equals sign before and after the intervention we used the adapted CES instrument described earlier. The 12 items are shown in Table 2. The same pre-test, intervention, post-test procedure was followed for both classes. During the lesson immediately preceding the intervention the modified CES instrument described above was administered to the children by their usual mathematics teachers. Teachers instructed children to complete the instrument individually under test conditions and to allow ten minutes to complete all 12 items. The order in which the statements were presented was randomised for each participant. The modified CES was administered again in the first available lesson after the intervention lessons had been completed. ${ }^{\text {iv }}$

The intervention took place over three one-hour lessons within a six day period and was delivered by the first author, referred to as the "teacher" here. In each class a data projector was available at the front of the classroom, and each child had a computer to his or herself, although two pairs of children had to share computers for two of the lessons in the rural school. During the first lesson the classes were shown how to use the software and then worked through puzzles designed by the research team. The plan for the first lesson is shown in Table 3. During the second lesson the classes continued with software-based puzzle solving, and also worked on paper-based and card-sorting versions of the puzzles during the middle section of the lesson. Pilots showed that nondigital versions of the puzzles are more difficult due to the lack of immediate feedback and so students worked in pairs rather than individually. Each pair was given 5 to 8 paper-based puzzles and 3 to 5 card-sorting puzzles to solve together. During the third lesson the classes began with software-based puzzle solving, and after a few minutes were shown how to use the software to make their own puzzles. They then made their own puzzles for much of the final lesson, which concluded with the teacher using 
directed whole class questioning to demonstrate how a selected child's mental addition strategy for solving $37+48$ can be represented as a puzzle.

Insert Table 3 about here

The software recorded data on the children's puzzle solving performance across the three lessons. The median, minimum and maximum number of puzzles solved was 38,10 and 76 respectively, and the median, minimum and maximum number of substitutions made was $131.5,17$ and 281 respectively. The software did not record data on the children's puzzle making performance although overall their difficulties and successes were comparable to those reported by Jones (2008).

The children worked individually with the software but were encouraged to help and discuss strategies with others sitting near to them. The teacher frequently paused the classes about every 10 to 15 minutes to ask for comments on the software and suggested strategies (e.g. "How do you decide which statement to start with?”), and to reflect on the activities (e.g. "Is solving puzzles the same or different to doing arithmetic?"). The classes were not told at any time about the three meanings for the equals sign operational, sameness-relational, substitutive-relational. This was to avoid children simply remembering what they had been told when completing the post-tests.

Analysis and results. Nine children who were absent during either the pre- or post-test were removed from the analysis. This left 45 participants. Children's ratings of the cleverness of the relational, substitutive and operational definitions were scored as 0 ("not so clever"), 1 ("sort of clever") or 2 ("very clever") for each definition shown in Table 2. Four participants had missed items and for three of these we replaced the empty cells with each participant's mean for other items for the same conception from 
the same time pre or post. One participant had missed all three substitutive items in the post-test and was excluded from the analysis, leaving a total of 44 participants.

To investigate the performance of the instrument we explored the internal consistency of the items making up each conception, as well as the distractor items, in the pre- and post-tests. For the operational items we obtained $\alpha_{\text {pre }}=.607$ and $\alpha_{\text {post }}=$ .697 ; for the substitutive-relational items $\alpha_{\text {pre }}=.736$ and $\alpha_{\text {post }}=.812$; for the samenessrelational items $\alpha_{\text {pre }}=.663$ and $\alpha_{\text {post }}=.741$; and for the distractor items $\alpha_{\text {pre }}=.071$ and $\alpha_{\text {post }}=.164$. This suggests that the items corresponding to equivalence conceptions performed satisfactorily, and as expected the three distractor items were not consistent. Each child had rated three definitions for each conception and so these summed to give a total score of 0 through to 6 for each conception. Participants' cleverness ratings for the three conceptions and distractor items are shown in Figure 3.

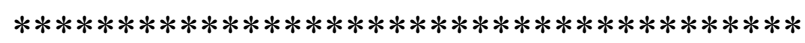

Insert Figure 3 about here

Cleverness ratings were subjected to an ANOVA with two within-subjects factors (conception: sameness-relational, substitutive-relational, operational, distractor; and time: pre-test, post-test). ${ }^{\mathrm{v}}$ There was a significant time $\times$ conception interaction effect, $F(3,129)=4.96, p=.003$. Post-hoc tests (Bonferroni-corrected $t$-tests) revealed that the mean post-test rating for the substitutive-relational conception (2.57) was significantly higher than the mean pre-test rating $(1.77), t(43)=2.80, p=.008$. Similarly, the mean post-test rating for the sameness-relational conception (3.41) was significantly higher than the mean pre-test rating $(2.73), t(43)=2.78, p=.008$. The mean post-test rating for the operational conception (4.00) was not significantly different to the mean pre-testing rating $(4.27), t(43)=1.23, p=.225$. Finally, the mean 
post-test rating for distractor items (1.57) was not significantly different to the mean pre-test rating $(1.25), t(43)=1.61, p=.114$.

We also undertook a one-way repeated measures ANOVA to investigate relative ratings of the three equivalence conceptions within the pre-test data, and within the post-test data. Analysis revealed a significant effect for conception at pre-test, $F(2,42)=$ $22.11, p<.001$, and at post-test, $F(2,42)=8.55, p<.001$. Post-hoc tests (Bonferronicorrected $t$-tests) revealed that there was a significant pre-test difference between the highest rated conception, operational, and the middle rated conception, samenessrelational, $t(43)=3.94, p<.001$. There was also a significant pre-test difference between the middle rated conception, sameness-relational, and the lowest rated conception, substitutive-relational, $t(43)=3.44, p=.001$. There was no significant posttest difference between the highest rated conception, operational, and the middle rated conception, sameness-relational, $t(43)=1.30, p=.199$. There was a significant post-test difference between the middle rated conception, sameness-relational, and the lowest rated conception, substitutive-relational, $t(43)=3.07, p=.004$.

Discussion. Study 2 measured how a sample of children in the first year of secondary schooling viewed the equals sign, and investigated the impact of an intervention in which children used non-canonical arithmetic statements to make substitutions of notation.

The pre-test data was as anticipated. We found that the children rated operational definitions the cleverest, sameness-relational definitions the next most clever, and substitutive-relational definitions the least clever prior to the intervention. Post-test data revealed increased cleverness ratings for substitutive-relational and sameness-relational definitions of the equals sign. Conversely, the children's cleverness ratings for operational definitions declined, although the difference between pre- and 
post-test was not significant. In sum, the children were more inclined to view the equals sign as a relation comprising sameness and substitutive components after the intervention than before it.

The children's increased endorsement of both sameness-relational and substitutive-relational items from pre- to post-test might have come about separately due to different aspects of the software, or alternatively might have come about because of concurrent development of the conceptions. One possibility is that sameness and substitution develop together, and that the overall increase was due to individual children either endorsing both or neither conceptions more strongly in the post-test. Another possibility is that the development of a substitutive-relational understanding comes only after the development of a sameness-relational understanding. If so, we would expect some children to endorse sameness but not substitution more strongly in the post-test, and we would not expect any children to endorse substitution but not sameness more strongly. In fact neither scenario was reflected in our data. Instead we found that 11 children more strongly endorsed both conceptions in the post-test than the pre-test, 9 children more strongly endorsed sameness but not substitution, and 10 children more strongly endorsed substitution but not sameness. This suggests it is a possibility there is no uniform order in which the two conceptions develop across individuals, at least when taught using the intervention described here. A larger, crosssectional study would reveal whether there are varied paths of conceptual development of symbolic equivalence across pupils.

\section{General Discussion}

We have presented two studies designed to investigate how the symbol " $="$ might commonly be presented in primary classrooms in England and measure 
conceptions of a sample of children in the first year of secondary school. We then measured the impact of a specially designed intervention on the children's conceptions.

In Study 1 we analysed how the equals sign is presented in statutory national written tests administered to children at the end of primary school in England. We found most occurrences were presented in canonical statements, suggesting that most postprimary children should be expected to view the equals sign as an operator rather than as signifying a relation. This is an unsurprising result that is often assumed to hold for England (e.g. Nunes, Bryant and Watson 2009; Jones 2008) but this is the first time that the presentation of "=" in primary classrooms in England has been directly investigated to the best of our knowledge. However, the result should be treated with caution due to the limitations of using national tests as a proxy for classroom resources that vary greatly in type and quality.

In Study 2 we measured how a sample of children in the first year of secondary school view the equals sign, and found they favoured an operational view. This provides support for the finding from Study 1. We note that Study 2 involved a relatively small sample of children, although the pre-test findings have been replicated with three larger samples of children in England by Jones, Inglis and Gilmore (2011) and Jones et al. (2012).

We then delivered a three lesson intervention in which children used arithmetic statements of varied formats to make substitutions of notation towards specified task goals. Analysis of pre- and post-test data showed a significant increase in cleverness ratings of both substitutive-relational and sameness-relational definitions of the equals sign. This confirms that the tasks designed to engage children with the structure of arithmetic statements in novel ways impact on conceptions of the equals sign, with a shift towards a more relational understanding. 
These findings have implications for theoretical accounts of how children move from an operational to a more relational understanding over their school careers. A consistent theme in the literature is a unidimensional progression from operational to sameness-relational conceptions (Behr et al. 1976; Carpenter et al. 2003; Rittle-Johnson et al. 2011). The findings reported in Study 2 challenge this dichotomous model by identifying substitution as an important aspect of a full relational understanding. Some children rated both sameness-relational and substitutive-relational definitions as more clever at post-test than at pre-test, others rated only sameness-relational or substitutiverelational definitions as more clever at post-test than at pre-test. As such there appears to be no consistent pattern behind this overall increase towards relational understanding. Further work is required to detangle which aspects of the intervention promoted sameness-relational views and which substitutive-relational views. Given our findings it is likely individual children responded differently to common aspects of the tasks such as the use of non-canonical statements, and the presentation of statements as rules for making transformations.

One implication of the operational to sameness-relational model is that children who strongly endorse sameness-relational conceptions should not be expected to strongly endorse operational conceptions. However this did not bear out in our data. The significant increase in sameness-relational views was not matched by a significant decrease in operational views. Further analysis revealed that in total 30 children increased their clever ratings of sameness-relational or substitutive-relational definitions following the intervention, but only 8 decreased their cleverness ratings of operational definitions. In addition there was no significant difference between sameness-relational and operational views in the post-test. Perhaps, then, development towards a more sophisticated understanding has more to do with complementing an operational view 
with sameness-relational and substitutive-relational views than it does with moving from an operational to sameness-relational view. We argue that future research should acknowledge the substitutive-relational conception, and explore how it relates to the operational and sameness-relational conceptions.

Our findings also have implications for teaching interventions that seek to foster a more relational understanding of arithmetic equivalence among children. As discussed earlier, operationalising relational understanding exclusively in terms of sameness affords very different design opportunities to the tasks used here. Future research into the impact of children evaluating the truthfulness of non-canonical statements, such as those shown in Table 1, should consider measuring substitutive-relational conceptions as well as operational and sameness-relational conceptions. Such work will provide further evidence towards understanding how the three conceptions under discussion relate to one another and develop towards a full relational understanding.

\section{Endnotes}

\footnotetext{
${ }^{\mathrm{i}}$ Referred to simply as the relational conception in the literature. We use the term samenessrelational to distinguish it from substitutive-relational, described above.

ii The Sum Puzzles software can be accessed online at www.sumpuzzles.org.

iii "Write the correct sign $<,>$ or $=$ " followed by three statements with empty boxes between two expressions, as in $10+5-9 \_10+9-5$. Our analysis was a count of printed equals signs and so this was coded as one occurrence.

${ }^{\text {iv }}$ Unfortunately, the rural school that participated in the study was closed due to adverse weather conditions for the week immediately following the intervention. Thus the post-test took place 10 days later than planned in this school. Nevertheless, there was not a main effect for school on any of the analyses described in this section, and nor did school interact with any other factor, so we do not believe that this influenced the results of the study in any significant fashion.

${ }^{v}$ We also conducted an ANOVA which included school as a between-subjects factor. But as there was no main effect of school, and neither did it interact with any other factor, we do not discuss it further.
} 


\section{Acknowledgement}

This project was funded by a grant from the Esmée Fairbairn Foundation. IJ is supported by a Royal Society Shuttleworth Educational Research Fellowship, MI is supported by a Royal Society Worshipful Company of Actuaries Educational Research Fellowship and C.G. is supported by a British Academy Postdoctoral Fellowship.

\section{References}

ACME. 2007. Position statement on functional mathematics. London: Advisory Committee on Mathematics Education.

Askew, M., J. Hodgen, S. Hossain, and N. Bretscher. 2010. Values and variables: mathematics education in high-performing countries. London: Nuffield Foundation.

Baroody, A. J. and H. P. Ginsburg. 1983. The effects of instruction on children's understanding of the "equals" sign. The Elementary School Journal 84, no. 2: 199-212.

Behr, M., S. Erlwange, and E. Nichols. 1976. How children view equality sentences Report No. PMDC-TR-3. Florida: Florida State University.

Capraro, R. M., M. M. Capraro, Z. E. Yetkiner, S. Özel, H. G. Kim, and A. R. KüçüK. 2010. An international comparison of Grade 6 students' understanding of the equal sign. Psychological Reports 106, no. 1: 49-53.

Carpenter, T. P., M. L. Franke, and L. Levi. 2003. Thinking mathematically: integrating arithmetic and algebra in the elementary school. Portsmouth, NH: Heinemann. 
Children, Schools and Families Committee. 2010. From Baker to Balls: the foundations of the education system. House of Commons ninth report of session 2009-10. London: The Stationary Office Ltd.

Cobb, P. 1987. An investigation of young children's academic arithmetic contexts. Educational Studies in Mathematics 18, no. 2: 109-124.

Denmark, T., B. Barco, and J. Voran. 1976. Final report: a teaching experiment on equality. Florida: Florida State University.

Jones, I. 2008. A diagrammatic view of the equals sign: Arithmetical equivalence as a means, not an end. Research in Mathematics Education 10, no. 2: 151-165.

Jones, I., M. Inglis, and C. Gilmore. 2011. Imperative and punctuative operational conceptions of the equals sign. Informal Proceedings of the British Society for Research into Learning Mathematics 31, no. 1: 79-84

Jones, I., M. Inglis, C. Gilmore, and M. Dowens. 2012. Substitution and sameness: Two components of a relational conception of the equals sign. Journal of Experimental Child Psychology 113, no. 1: 166-76.

Jones, I. and D. Pratt. 2012. A substituting meaning for the equals sign in arithmetic notating tasks. Journal for Research in Mathematics Education 43, no. 1: 2-33.

Kieran, C. 1981. Concepts associated with the equality symbol. Educational Studies in Mathematics 12, no. 3: 317-326.

Knuth, E. J., A. C. Stephens, N. McNeil, and M. W. Alibali. 2006. Does understanding the equal sign matter? Evidence from solving equations. Journal for Research in Mathematics Education 36, no. 4: 297-312.

Li, X., M. Ding, M. M. Capraro, and R. M. Capraro. 2008. Sources of differences in children's understandings of mathematical equality: Comparative analysis of 
teacher guides and student texts in China and the United States. Cognition and Instruction 26, no. 2: 195-217.

McNeil, N. 2004. You'll see what you mean: Students encode equations based on their knowledge of arithmetic. Cognitive Science 283, no. 3: 451-466.

McNeil, N. 2007. U-shaped development in math: 7-year-olds outperform 9-year-olds on equivalence problems. Developmental Psychology 43, no. 3: 687-695.

McNeil, N. 2008. Limitations to teaching children $2+2=4$ : Typical arithmetic problems can hinder learning of mathematical equivalence. Child Development 79, no. 5: 1524-1537.

McNeil, N. and M. W. Alibali. 2002. A strong schema can interfere with learning: The case of children's typical addition schema. In Proceedings of the Twenty-Fourth Annual Conference of the Cognitive Science Society, ed. C. Schunn and W. Gray, 661-666. Mahwah, NJ: Lawrence Erlbaum Associates.

McNeil, N. and M. W. Alibali. 2005. Why won't you change your mind? Knowledge of operational patterns hinders learning and performance on equations. Child Development 76, no. 4: 883-899.

McNeil, N., E. R. Fyfe, L. A. Petersen, A. E. Dunwiddie, and H. Brletic-Shipley. 2011. Benefits of practicing $4=2+2$ : Nontraditional problem formats facilitate children's understanding of mathematical equivalence. Child Development 82, no. 5: 1620-1633.

McNeil, N., L. Grandau, E. J. Knuth, M. W. Alibali, A. C. Stephens, S. Hattikudur, and D. E. Krill. 2006. Middle-school students' understanding of the equal sign: The books they read can't help. Cognition and Instruction 24 no. 3: 367-385. 
Molina, M., Encarnación Castro, and Enrique Castro. 2009. Elementary students’ understanding of the equal sign in number sentences. Electronic Journal of Research in Educational Psychology 7, no. 1: 341-368.

Mullis, I. V. S., M. O. Martin, P. Foy, J. F. Olson, C. Preuschoff, E. Erberber, A. Arora et al. 2008. TIMSS 2007 International mathematics report: findings from IEA's trends in international mathematics and science study at the fourth and eighth grades. Chestnut Hill, MA: TIMSS and PIRLS International Study Center, Boston College.

NCETM. 2009. Mathematics matters: final report. London: National Centre for Excellence in the Teaching of Mathematics.

Nunes, T., P. Bryant, and A. Watson. 2009. Key understandings in mathematics learning. London: The Nuffield Foundation.

Ofsted. 2008. Mathematics: understanding the score. London: Office for Standards in Education.

Pirie, S. and L. Martin. 1997. The equation, the whole equation and nothing but the equation! One approach to the teaching of linear equations. Educational Studies in Mathematics 34, no. 2: 159-181.

QCA. 2004. Key Stage 2 Mathematics Test B Levels 3-5. Retrieved September 1, 2011 from http://www.emaths.co.uk/KS2SAT.htm

Renwick, E. M. 1932. Children's misconceptions concerning the symbols for mathematical equality. British Journal of Educational Psychology 2, no. 2: 173183.

Rittle-Johnson, B. and M. W. Alibali. 1999. Conceptual and procedural knowledge of mathematics: Does one lead to the other? Journal of Educational Psychology 91, no. 1: 175-189. 
Rittle-Johnson, B., P. Matthews, R. S. Taylor, and K. L. McEldoon. 2011. Assessing knowledge of mathematical equivalence: A construct-modeling approach. Journal of Educational Psychology 103, no. 1: 85-104.

Sáenz-Ludlow, A. and C. Walgamuth. 1998. Third graders' interpretations of equality and the equal symbol. Educational Studies in Mathematics 35, no. 2: 153-187.

Seo, K. H., and Ginsburg, H. P. 2003. "You've got to carefully read the math sentence...": Classroom context and children's interpretations of the equals sign. In The Development of Arithmetic Concepts and Skills: Constructing Adaptive Expertise, ed. A. J. Baroody and A. Dowker, 161-187. Mahwah, NJ: Lawrence Erlbaum Associates Publishers.

Sherman, J. and J. Bisanz. 2009. Equivalence in symbolic and nonsymbolic contexts: benefits of solving problems with manipulatives. Journal of Educational Psychology 101, no. 1: 88-100.

Wyse, D. and H. Torrance. 2009. The development and consequences of national curriculum assessment for primary education in England. Educational Research 51, no. 2: 213-228. 
Table 1. Example arithmetic statements that appeal to arithmetic principles. Taken from Molina, Encarnación Castro and Enrqiue Castro, 2009, p.351.

\begin{tabular}{|c|c|c|}
\hline $10+4$ & $4+10$ & commutativity \\
\hline $13+11$ & $=12+12$ & compensation \\
\hline $100-94+94$ & $=100$ & inversion \\
\hline
\end{tabular}


Table 2: Definitions of the equals sign presented in the Conceptions of the Equals Sign instrument.

\begin{tabular}{ll}
\multicolumn{1}{c}{ Definitions: $=$ means... } & Conception \\
\hline ...the answer to the problem & Operational \\
... work out the result & Operational \\
...the total & Operational \\
...that two amounts are the same & Sameness-relational \\
...both sides have the same value & Sameness-relational \\
...that something is equal to another thing & Sameness-relational \\
...one side can replace the other & Substitutive-relational \\
...that the right-side can be swapped for the left-side & Substitutive-relational \\
$\ldots$ that two sides can be exchanged & Substitutive-relational \\
...the end of the problem & Distractor \\
$\ldots$ the start of the problem & Distractor \\
...to repeat the numbers & Distractor \\
\hline
\end{tabular}


Table 3: Lesson plan for the first of the three lesson interventions. In practice pupils worked mostly one to a computer rather than in pairs during the lessons.

\begin{tabular}{ll}
\hline Time & Activity \\
\hline 0 & Introduce self and lesson \\
& Demonstrate how the software works on IWB: selecting statements by clicking an equals sign \\
& and making substitutions by clicking in the boxed expression. Explain the task goal is to use \\
& statements to transform he expression into its 'answer'. \\
& "Sometimes it lets me make a substitution and sometimes it doesn't. Work out why."; "Try \\
& and solve some puzzles. Can you find and explain an efficient strategy for doing so?" \\
& Pupils work in pairs. Log on to PCs and work through first set of puzzles. \\
& Researcher circulates and assists. \\
\hline 10 & Whole class discussion. "When can you make substitutions?" \\
& "What strategies have you developed?" \\
\hline 50 & Pupils continue solving puzzles in pairs. If pupils finish the first set of puzzles they move on \\
& to the second and third sets. \\
\hline 60 & Whole class discussion. \\
& "What is it like doing these puzzles compared to doing arithmetic worksheets? "; "What is the \\
\hline & Lesson ends
\end{tabular}


Figure 1. An example puzzle in the Sum Puzzles software.

\section{$31+67$}

$$
\begin{array}{ll}
67=60+7 & 1+7=8 \\
30+60=90 & 31=30+1 \\
90+8=98 & 1+60=60+1
\end{array}
$$


Figure 2: Example question containing equals signs in the form letter $=$ result from the statutory tests for primary children in England taken from QCA, 2004.

Here are five number cards.

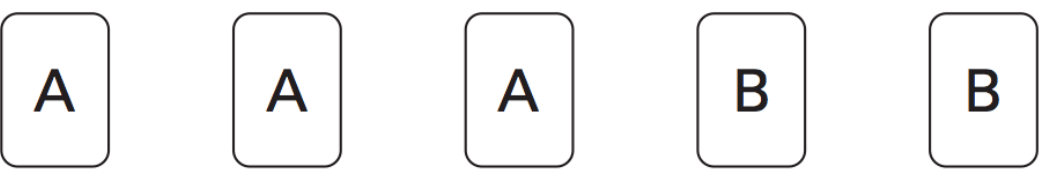

$A$ and $B$ stand for two different whole numbers.

The sum of all the numbers on all five cards is 30

What could be the values of $A$ and $B$ ?

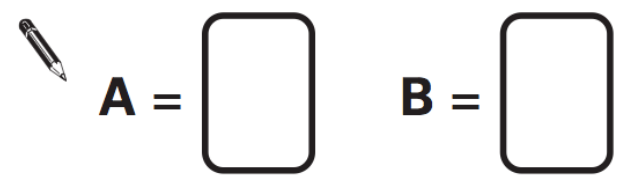


Figure 3: Children's cleverness ratings of the three different conceptions of the equals sign, on pre- and post-test. Error bars show standard error of means.

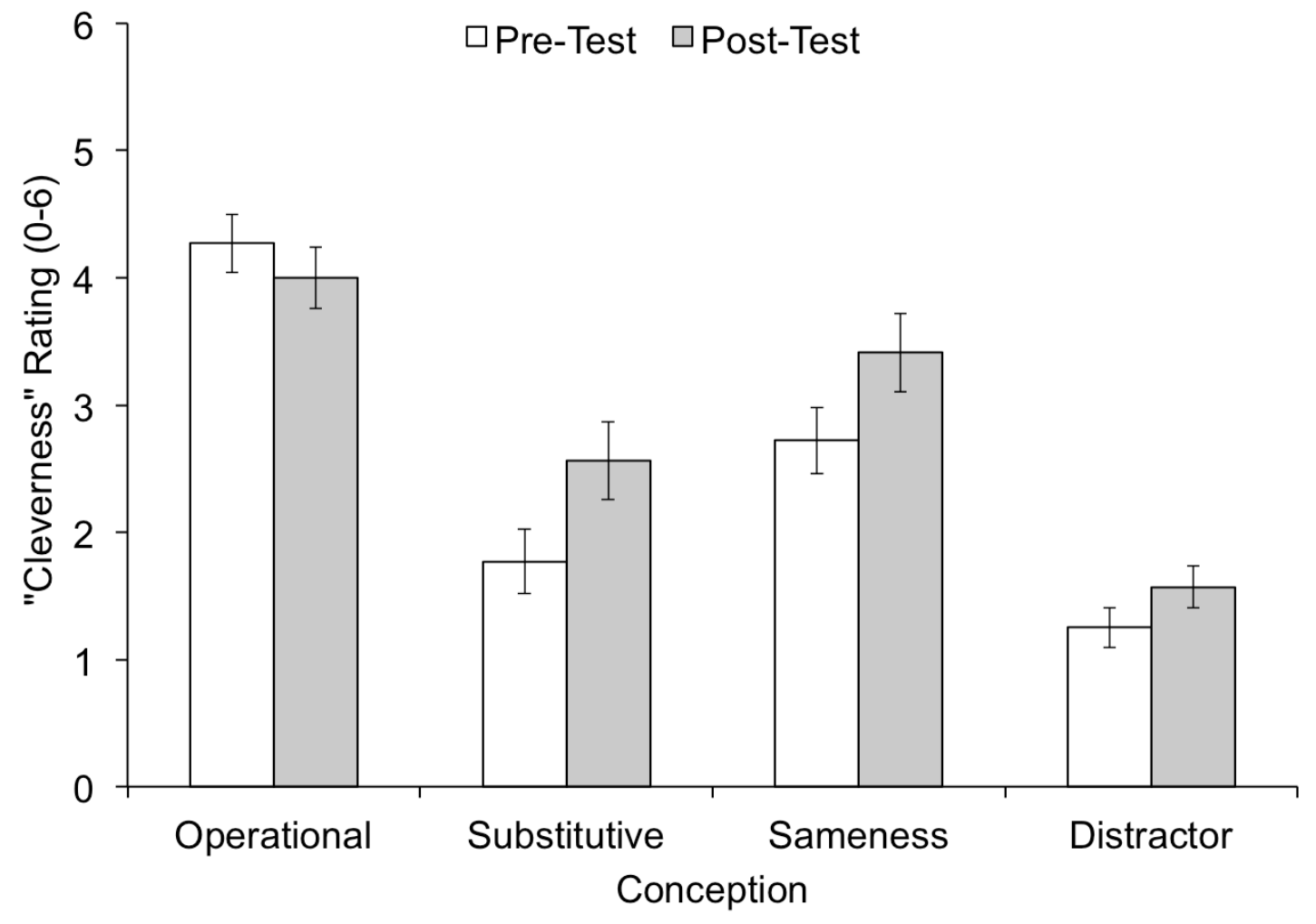

